\title{
Embryo research and abortion
}

The British government's promised bill on embryo research, now imminent, seems bound to provoke an unwanted argument on abortion. But it is not too late to amend the bill and make it better.

ONE consequence of the British government's delay in bringing forward its promised bill to implement the recommendations of the Warnock committee on in vitro fertilization (IVF) and related matters is that opponents of legalized abortion have had time to organize themselves so as to seize the opportunities with which the bill will provide them. The bill will be part of the government's legislative programme for the next parliamentary session, due to be announced by the Queen next month. Meanwhile, the government has leaked news of its willingness that the time-limit for abortion should be reduced from 28 to 24 weeks of gestation. That is a sensible step, although it will not, unfortunately, satisfy the critics of abortion.

That the two issues are connected is uncomfortably undeniable, at least on a strict reading of the Warnock recommendations. The committee, faced with the need to say when it would be permissible to persist with the observation of artificially fertilized human embryos, recommended that all such research should require the approval of a new statutory body, but that in no case should embryos remain viable for more than 14 days. That time was chosen to be less than that at which, in the normal embryo, the nervous system begins to develop. Ostensibly, such an immature embryo could not be supposed to feel pain. More primitively, but excusably, the members of the committee took the view that the central nervous system is the embodiment of the soul. The obvious difficulty is that anti-abortionists are entitled to demand that naturally fertilized embryos should have the same protection as Warnock recommends.

This is a debating point, but none the less influential on that account. The underlying difficulty is that the Warnock recommendations over-insure against the abuse of human embryos by researchers. That there should be a statutory procedure by which all investigations must be approved is undisputed. By now, thanks to the experience of the committees regulating the development of the genetic manipulation of organisms, there is ample experience that statutory procedures can work efficiently and in a manner that commands the respect of researchers. What reason is there to fear that the proposed replacement of the present committee on IVF by a statutory body will be less well organized? And what reason can there be for supplementing that statutory regulation by the arbitrary requirement that no observations of an artificially fertilized embryo should extend beyond 14 days?

The public interest that human embryos should be accorded the respect they deserve, and the Warnock committee's inclinations, could just as well be secured by requiring that the new statutory committee should be satisfied that any proposed observation on or experiment with an artificially fertilized embryo should build on knowledge already firmly established, that there is a high chance that they will yield the information expected of them and that that information, if gathered, would contribute in some substantial way to the understanding of the distinctive characteristics of human life and its preservation in a healthy state. Working with such guidelines, no statutory committee would be likely to sanction the study of a human embryo when, for example, a mouse embryo would suffice. That is why, even at this late stage, the government should scrap the arbitrary time limit wished on it by the Warnock committee.

\section{California lessons}

Earthquake protection is plainly possible, as the Californian earthquake showed. But who else can afford it?

CALIFORNIANS are almost as taken aback that last week's earthquake should have killed fewer than 200 people as by the circumstance that there should have been a further relief of stress on the San Andreas Fault (see pages 676 and 677). In spite of the tragedy that now afflicts the families bereaved and, many more, those without housing, it is literally astonishing that an urban earthquake essentially of the same magnitude as that which killed 25,000 people in Armenia last December should have done so little damage.

The explanation is simple: California's building codes, which the state has been progressively tightening since the San Francisco earthquake of 1906. The codes have been developed so that San Francisco and Los Angeles now sport metropolitan cities' shares of tall buildings, but there has also been immense attention to detail. Just five years ago, owners of wooden frame buildings were required to bolt them to the concrete foundations on which they rest when it emerged that structures of that kind could easily be shaken off their pedestals by sufficiently strong earthquakes. The regular rehearsals of the 